\title{
Investigating Multiple Representations Ability of High School Students on Linear Motion
}

\author{
Irvany Nurita Pebriana*, Supahar Supahar, Pramudya Wahyu Pradana*, \\ Mundilarto Mundilarto
}

Physics Education Department, Faculty of Mathematics and Natural Sciences, Universitas Negeri Yogyakarta,
Indonesia
*Corresponding author. Email: irvany.nurita@uny.ac.id, pramudyawahyu.2017@student.uny.ac.id

\begin{abstract}
This study investigated the multiple representations ability of high school students on linear motion in the aspect of the ability to represent various forms of representation and the ability to translate between representations. The representation records included verbal, graphs, diagrams, mathematics, and tables. This research was conducted by conducting tests on respondents consisting of 301 high school students who were randomly selected and studied linear motion. The analysis was carried out using IRT PCM 1PL with the help of the Quest program to determine students' ability scores $(\theta)$ and descriptive statistics for more detailed information. The results show that students tend to have low multiple representations ability $(\theta=-1.20)$ in all aspects of various representations. This finding implies that more attention is needed to improve the ability of multiple representations, and it is necessary to synchronize the physics and mathematics curriculum to support the improvement of multiple representation ability
\end{abstract}

Keywords: High school students, Linear motion, Multiple representations

\section{INTRODUCTION}

Multiple representations are essential for a student to have when learning physics. The ability to represent the concept using various forms of representation and translate among representations is the most vital competence for understanding the whole ideas of physics [1][2]. Physics concepts can be presented in various forms of representation. Several studies have shown that students who study physics by utilizing multiple representation abilities are proven to be better in understanding physics concepts [3][4][5], able to improve scientific literacy skills [6], and able to enhance problem-solving abilities [7]. The use of more representations in learning can have a positive influence on the learning process and make it easier for students to recall the material taught from long-term memory [8][9].

Although multiple representations ability provides many benefits, this ability has not been given much attention in classroom learning. The lack of attention to multiple representations can be seen from the existence of students with low multiple representation abilities [10]. Furthermore, according to [11], many students have representational abilities dominated by mathematical representations.

Experts and practitioners have conducted numerous studies to alleviate students from these problems. Many researchers focused their study on learning methods to improve students' multiple representations ability. The learning methods were recommended because they are proven to be able to improve students' multiple representations abilities include (i) virtual concrete learning model [12], (ii) learning with simulation and observation learning model [13], (iii) learning that requires students to analyse videos about natural phenomena [14], and (iv) learning using simulation methods [15]. In addition to developing various learning models, many researchers also develop various learning media to improve the ability of multiple representations of students. Various media developed include androidbased physics learning media integrated with local 
wisdom that can improve argumentative representation and diagrammatic representation [16] and online learning module (OLM) which is proven to increase the capacity of multiple representation [17]. These efforts certainly cannot improve the multiple representations ability of students effectively without the support of a valid and reliable assessment of this ability.

One of the alternative assessments that can be used to assess multiple representations ability is a mapping survey of students' multiple representations. There have been many surveys on the mapping of students' multiple representations, for example, researches by [10][11][18][19]. However, this survey can only provide information on multiple representations on a fairly limited variety of representations so that the survey results do not provide comprehensive information about students' abilities. Some studies only provide an overview of students' multiple representations on several representations [10][11][18][19]. Some other studies even only provide information on students' multiple representations on one representation, such as only verbal representation [20], picture representation [21], mathematical [22][23], or symbolic representation [24].

This study investigated students' multiplerepresentation ability measured in more complete aspects of multiple representations than previous studies. Moreover, this study investigated the multiple representations of students by reviewing the ability to represent various forms of representation and the ability to translate between representations. Because the ability to express one topic is not related to other issues [25], it is essential to identify the knowledge of multiple representations in physics for each case of discussion. However, due to limitations, we limit our investigation to the topic of linear motion. This topic is a fundamental physics topic that can be represented in various forms of representation. It shows that assessing students' multiple representations ability on this material with a more diverse representation aspect is critical to improving the performance of students' physics learning.

\section{RESEARCH METHOD}

This research is a descriptive study that aims to investigate the ability of multiple representations of students on the material of linear motion. The research was conducted using a survey technique to capture the multiple representations ability of students.

\subsection{Research Instrument}

The research instrument used in this study is a twotier multiple-choice test instrument to measure the multiple representations ability of students on linear motion. The tool consists of 20 items with 15 items measuring students' representational abilities in the form of verbal representations, graphs, diagrams, mathematics, tabular, and five items to measure the ability to translate between forms of representation. The 15 items that measure the ability to represent many forms of representation are divided into three contexts: the context of acceleration, speed-velocity, and distance-displacement. Each context counts the five states of representation. Table 1 shows the distribution of questions for each aspect of representation.

Table 1. Distribution of questions for each aspect of the representation

\begin{tabular}{|c|l|l|}
\hline No & Aspect of Representations & Amount of Item \\
\hline 1 & Verbal & 3 \\
\hline 2 & Graph & 3 \\
\hline 3 & Mathematical equation & 3 \\
\hline 4 & Diagrams & 3 \\
\hline 5 & Table & 3 \\
\hline 6 & $\begin{array}{l}\text { Translation among } \\
\text { representations }\end{array}$ & 5 \\
\hline
\end{tabular}

The results of the content validity analysis showed that all items of the instrument met the criteria for content validity. At the same time, the results of the item analysis of the questions show that all items have good reliability.

The scoring model used in this study is the M5 scoring model from the study of Xiao [26]. This scoring model was chosen because it has a good model fit performance and can provide more detailed information on students' abilities.

\subsection{Respondents}

Respondents in this study were high school students who had studied linear motion with a total of 301 students. All respondents are students from five schools in Central Java and the Special Region of Yogyakarta, Indonesia, who were selected using the cluster random sampling technique.

\subsection{Data Collection and Data Analysis}

Data collection was carried out in April-May 2021 by doing tests on respondents. The data was obtained in the form of student score data. This score is then analysed using the Partial Credit Model (PCM) 1 PL model by utilizing the Quest program. This program analysed the value of the student's ability parameter, which describes the general multiple representations ability. Students' raw scores were analysed with descriptive statistics to determine students' abilities in each aspect of multiple representations in more detail.

\section{RESULT AND DISCUSSION}

Results show information on the multiple representations ability of students in general through the 
value of $\theta$. The distribution of students' abilities is briefly described in the histogram in Fig. 1.

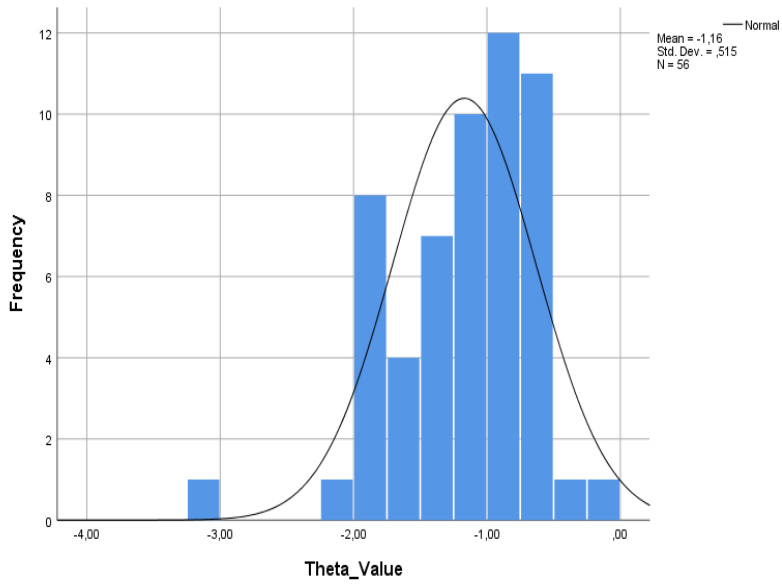

Figure 1 Histogram of the $\theta$ value distribution of respondents

The histogram in Fig. 1 shows that the student's abilities are quite random, with the average ability being at $\theta=-1.20 \pm 0.53$. Although most of the students' abilities are in the standard deviation range of values, it turns out that there are a small number of students who have the ability with values close to -3.00 . The value of $\theta$ describes students' ability in general after answering all the questions. In more detail, the ability of students can be read by describing the raw scores of students.

Students' raw scores are given based on the M5 answer pattern according to the scoring model by Xiao [26], which consists of three scores, namely 0,1 , and 2 . score of 0 indicates that students have not been able to use multiple representations well or perform guesses. A score of 1 indicates that students can answer the question correctly but cannot explain why the answer is correct. While a score of 2 indicates that students can answer questions correctly and explain the reasons for choosing these answers. The results of the analysis of the raw scores can be seen in Fig. 2 to Fig. 5.

Fig. 2 illustrates the percentage of students who answered with a score of 2 and a score of 1 in each form of representation for each context. The percentage of students to answer a score of 2 and a score of 1 on this graph illustrates that in general students have a low ability to represent the concept of Linear motion in various forms because they are at a percentage of less than $45 \%$ for each context and each form of representation.

The graph in Fig. 2 illustrates that the representation ability of students is still dominant in the graphical, table, and verbal representations. It is reinforced by the percentage of the number of students in obtaining a score of 2 , which is still dominant in the three forms of representation. The average distribution of students in obtaining a score of 1 indicates that there is a possibility that $6-12 \%$ of students have answered correctly but have not been able to provide an appropriate explanation. Symptoms of students' high verbal representation ability arise because the material of linear motion is usually explained in words [27]. The percentage of students for each score and the five forms of representation can be seen in Fig. 3.

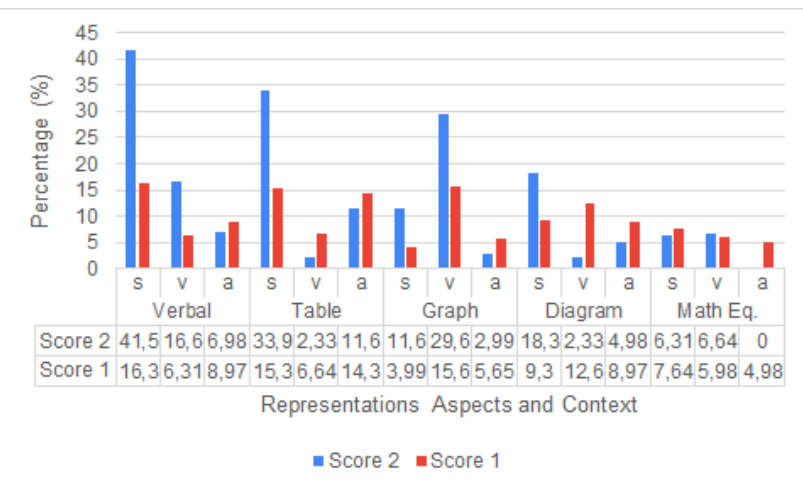

Figure 2 Distribution score for each representational ability in each context

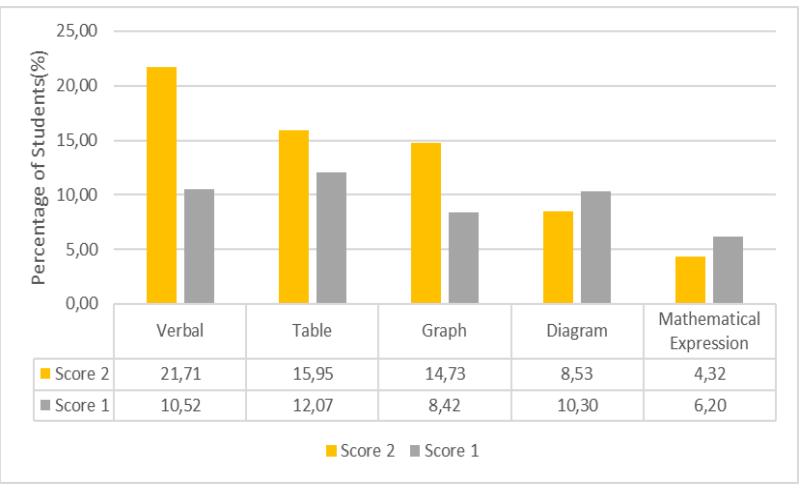

Figure 3 Graph of the percentage of students in answering correctly for each representation ability

The general representation ability of students in each context is depicted through the graph in Fig. 4. From the chart, it can be seen that the representation ability of students for each context is still low, showing below $20 \%$ got a score of 2 or 1 . The graph shows that many students who earned a score of 2 and a score of 1 had a dominant representational ability in the context of distance-displacement ( $\mathrm{s}$ ).

The number of students who got a score of 1 did not differ significantly in the three contexts. If we look further, the percentage of students who earn a score of 1 on the graphs of Fig. 3 and Fig. 4 is also not too significant. It shows that in the range of $6-12 \%$ of the total respondents, it is possible to have difficulty explaining the reasons for giving answers. 


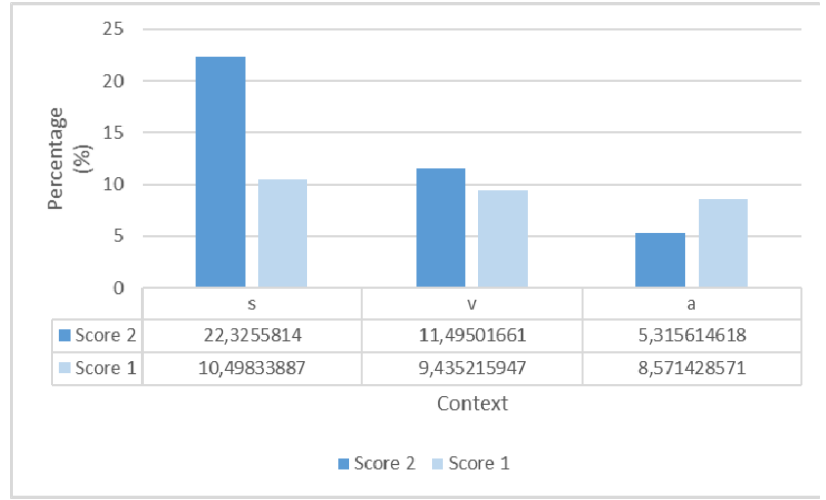

Figure 4 Percentage of students who get a score of 2 and a score of 1 for each context

The percentage of students obtaining a score of 2 and a score of 1 for representational translation questions can be seen in the graph in Fig. 5. From the chart, it can be observed that most of the students have low representative translation ability. The percentage of students who answered the representation translation problem with a score of 2 in the range of $1.3-39.5 \%$. The dominant distribution of students with a score of 2 occurs in the translation of graphic representations into mathematics (G-M).

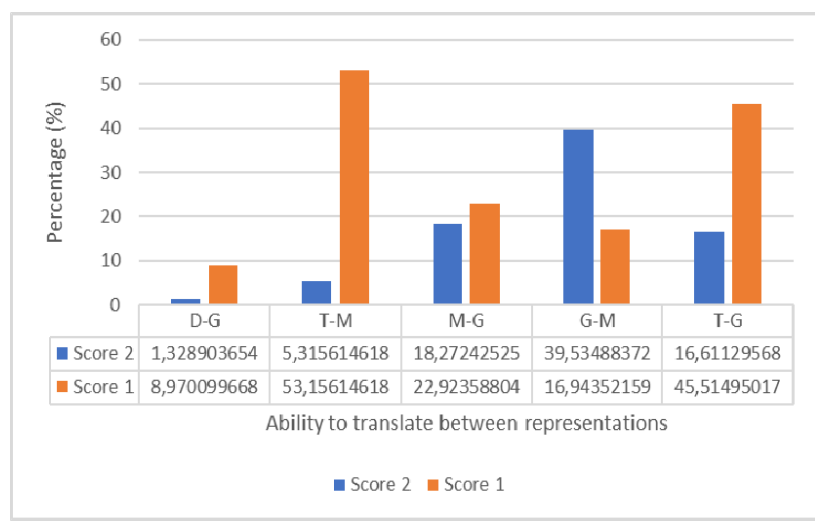

Figure 5 Graph of the student's percentage who get scores 1 and 2 for the representation translation ability

The graph in Fig. 5 shows that more respondents answered a score of 1 than 2 . The distribution of score 1 is dominant in the translation of table to mathematical representations (T-M) and tables to graphs (T-G). The number of students getting a score of 1 , which is more than the students who get the score of 2 , indicates that more students have difficulty providing explanations for cases of representation translation. Students' challenges in delivering the right reason may be due to the addition of a second-tier which is confusing for students.

Figure 2 and Figure 3 illustrate poor mathematical representation abilities, with the number of students who scored one being higher than students who scored 2. It is different from the finding of [11], which states that the multiple representation ability of students in Indonesia, especially in large islands, is dominant in mathematical representation. The cause of the low mathematical representation ability is due to common mathematical knowledge or understanding of concepts [28] and students who are not familiar with variations in the form of questions [29]. This finding shows that learning mathematics as the basis for learning physics has not been taught properly. Therefore, adjustments to the physics and mathematics curriculum in schools need to be made to increase the understanding of physics concepts and the multiple representation ability of high school students.

The finding that less than $55 \%$ of students answered with a 2 and a score of 1 represent the ability of respondents to make representations tend to be low and the ability to translate representations. It indicates that respondents have low multiple representations abilities. In addition, the multiple representations ability $\theta$ is at a negative value, precisely in the range of -1.20 .

\section{CONCLUSION}

The research concludes that most respondents have multiple representations abilities in low scores $(\theta=$ 1.20) in representing various forms of representation and representational translation.

This finding implies that there should be more attention to increasing the multiple representations of high school students in learning physics, especially in verbal, table, graph, diagram, and mathematical representations. In addition, there is a need for integrating mathematics and physics at the high school level so that students' physics learning performance can be improved with mathematical abilities as the foundation.

\section{ACKNOWLEDGMENTS}

Thanks to the Faculty of Mathematics and Natural Sciences for generous financial support. We are grateful to Suparno, Ph.D. provided ideas and valuable feedback on the manuscript. We would also like to thank all of the teachers of SMA Negeri 1 Kebumen, SMA Negeri 1 Ngemplak, SMA Negeri 2 Ngaglik, SMA Negeri 5 Yogyakarta, and SMA Negeri 1 Cangkringan who have used this instrument to be implemented in their course.

\section{REFERENCES}

[1] P. Klein, A. Müller, and J. Kuhn, Assessment of representational competence in kinematics, Phys. Rev. Phys. Educ. Res., (2017), vol. 13, no. 1, pp. 1-18, Jun. 2017, doi: https://doi.org/10.1103/PhysRevPhysEducRes.13.0 10132

[2] V. Prain, and B. Waldrip, An exploratory study of teachers' and students' use of multi-modal 
representations of concepts in primary science, Int. J. Sci. Educ., vol. 28, no. 15, pp. 1843-1866, Feb. 2007 , doi: https://doi.org/10.1080/09500690600718294

[3] E. Campos, G. Zavala, K. Zuza, and J. Guisasola, Electric field lines: The implication of students' interpretation on their understanding of the concept of electric field and the superposition principle, Amer. J. Phys., vol. 87, no.8, pp.660-667, Jul. 2019, doi: 10.1119/1.5100588.

[4] P. Nieminen, A. Savinainen, and J. Viiri, Relations between representational consistency, conceptual understanding of the force concept, and scientific reasoning, Phys. Rev. ST Phys. Educ. Res., vol. 8, no. 1, pp.1-10, May 2012, doi: https://doi.org/10.1103/PhysRevSTPER.8.010123.

[5] van Heuvelen, Learning to think like a physicist: A review of research-based instructional strategies, Amer. J. Phys., vol.59, no.10, pp. 891-897, Jul. 1998, doi: https://doi.org/10.1119/1.16667.

[6] S. Nitz, H. Prechtl, and C. Nerdel, Survey of classroom use of representations: development, field test and multilevel analysis, Learn. Environ. Res., vol. 17, no. 3, pp. 401-422, Oct. 2014, doi: https://doi.org/10.1007/s10984-014-9166-x.

[7] L. Bollen, P. van Kampen, C. Baily, M. Kelly, and M. de Cock, Student difficulties regarding symbolic and graphical representations of vector fields, Phys. Rev. Phys. Educ. Res., vol. 13, no. 2, pp. 1-17, Aug. 2017, doi:https://doi.org/10.1103/PhysRevPhysEducRes. 13.020109 .

[8] E. Adadan, Using multiple representations to promote grade 11 student's scientific understanding of the particle theory of matter, Res. in Sci. Educ., vol. 43, no. 3, pp. 1079-1105, Jun. 2013, doi: https://doi.org/10.1007/s11165012-9299-9.

[9] D.F Treagust and C-.Y. Tsui, Introduction to multiple representations: The importance in biology and biological education, in Multiple Representations in Biological Education, Series: Models and Modeling in Science Education, D. F. Treagust and C-. Y. Tsui, Ed., Dordrecht, Netherlands: Springer, 2013, pp. 19-38.

[10] M. Furqon and Muslim, Investigating the ability of multiple representations and scientific consistency of high school students on newton's laws, J. Phys.: Conf. Ser., vol. 1280, no. 5, Nov. 2019, doi: https://doi.org/10.1088/1742-6596/1280/5/052041.
[11]I. Kusumawati, M. S. Kahar, A. Khoiri, and A. Mursidi, Differences analysis understanding the concept of students between the three islands (Java, Kalimantan, Papua) through multiple representations approaches to the material of Time Dilation, J. Phys.: Conf. Ser., vol. 1153, no.1, Feb.2019, doi: https://doi.org/10.1088/17426596/1153/1/012145.

[12]A. T. Stull and M. Hegarty, Model manipulation and learning: Fostering representational competence with virtual and concrete models, $J$. Educ. Psychol., vol. 108, no. 4, pp. 509-527, 2016 , doi: https://doi.org/10.1037/edu0000077.

[13]Z. R Ridlo, Sutarto, I. K. Mahardika, Indrawati, I. W. A. Terra, and E. Wardani, Student profile multiple representations skills under the implementation of OBSIM (observation and simulation) model of teaching in improving creative thinking skills, J. Phys.: Conf. Ser., vol. 1563 , no. 1, Jun. 2020, doi: 10.1088/1742 6596/1563/1/012027.

[14] K. Hochberg, S. Becker, M. Louis, P. Klein, and J. Kuhn, Using Smartphones as experimental tools a Follow-up: cognitive effects by video analysis and reduction of cognitive load by multiple representations, J. Sci. Educ. and Technol., vol. 29 , no. 2, pp. 303-317, Feb. 2020, doi: 10.1007/s10956-020-09816-w.

[15] K. Nichols, M. Ranasinghe, and J. Hanan, Translating between representations in a social context: A study of undergraduate science students' representational fluency, Instructional Sci., vol 41, no. 4, pp. 699-728, Jul. 2013, doi: https://doi.org/10.1007/s11251-012-9253-2.

[16]N. Liliarti and H. Kuswanto, Improving the competence of diagrammatic and argumentative representation in physics through android-based mobile learning application, Int. J. Instruction. vol. 11, no. 3, pp. 107-122, Jul. 2018.

[17] M. Hill, M. D. Sharma, and H. Johnston, How online learning modules can improve the representational fluency and conceptual understanding of university physics students, Eur. J. Phys., vol. 36, no. 4, Jun. 2015, doi: https://doi.org/10.1088/0143-0807/36/4/045019.

[18]B. K. Prahani et.al., A profile of physics multiple representation ability of senior high school students on heat material, J. Phys.: Conf. Ser., vol. 1760, no. 1, 2021, doi: https://doi.org/10.1088/1742-6596/1760/1/012020.

[19]R. S. Waremra, M. Simbolon, S. Bahri, and O. Dadi, Profiles of student representation types to 
solve problems in physics learning. Gravity: Jurnal Ilmiah Penelitian Dan Pembelajaran Fisika, vol. 7, no. 1, pp. 36-41, Feb. 2021, doi: https://doi.org/10.30870/gravity.v7i1.9567.

[20] A. M. R. Tumanggor, Supahar, and M. F. T. Nirmala, The development of diagnostic test instrument for verbal representation ability in high school physics learning, in Proc. of the 7th Int. Conf. on Res., Implement., and Educ. of Math. and Sci., 2021, pp. 471-476. doi: https://doi.org/10.2991/assehr.k.210305.069.

[21] M. F. T. Nirmala, A. M. R. Tumanggor, and Supahar, Analysis of validity and reliability of diagnostic test of picture representation ability in high school physics learning, in Proc. of the 7th Int. Conf. on Res., Implement., and Educ. of Math. and Sci., 2021, pp. 538-546. doi: https://doi.org/10.2991/assehr.k.210305.079

[22]A. M. R. Tumanggor and Supahar, The development of diagnostic test instrument for mathematical representation ability (PhysDTRA) in high school physics learning, J. for the Educ. of Gifted Young Scientists, vol. 8, no. 4, pp. 14391453, Dec. 2020, doi: https://doi.org/10.17478/jegys.777425.

[23] A. M. R. Tumanggor and Supahar, Dissemination of online diagnostic test instrument to diagnose high school students' mathematical representation ability: The case of work and energy, in Proc. of the 6th Int. Seminar on Sci. Educ., 2021, pp. 528537. doi: https://doi.org/10.2991/assehr.k.210326.076

[24] M. F. T. Nirmala, Supahar, and S. Sundari, Dissemination of symbolic representation ability in high school physics subjects, J. Phys.: Conf. Ser., vol. 1440, no. $1, \quad 2020, \quad$ doi: https://doi.org/10.1088/1742-6596/1440/1/012056

[25]H.-Y. Chang, Student's representational competence with drawing technology across two domains of science, Sci. Educ., vol. 102, no. 5, pp. 1129-1149, Jun. 2018, doi: https://doi.org/10.1002/sce.21457.

[26] Y. Xiao, J. Han, K. Koenig, J. Xiong, and L. Bao, Multilevel Rasch modeling of two-Tier multiplechoice test: A case study using Lawson's classroom test of scientific reasoning, Phys. Rev. Phys. Educ. Res., vol. 14, no. 2 Jul. 2018, doi: https://doi.org/10.1103/PhysRevPhysEducRes.14.0 20104

[27]M. de Cock, Representation use and strategy choice in physics problem solving, Phys. Rev. ST Phys. Educ. Res., vol 8, no. 2, pp. 1-15, Nov. 2012, doi:

https://doi.org/10.1103/PhysRevSTPER.8.020117

[28] M. M. Chusni, Suranto, S. B. Rahardjo, and S. Saputro, Profile of multi-modal representation ability of junior high school students on science material in Sleman district, J. Phys.: Conf. Ser., vol. 1511, no. 1, Apr. 2020, doi: https://doi.org/10.1088/1742-6596/1511/1/012107.

[29] A. T. Saputra, J. Jumadi, D. W. Paramitha, and S. Sarah, Problem-solving approach in multiple representations of qualitative and quantitative problems in kinematics motion, Jurnal Ilmiah Pendidikan Fisika Al-Biruni, vol. 8, no. 1, pp. 8998, Apr. 2019, doi: https://doi.org/10.24042/jipfalbiruni.v8i1.3801. 